\title{
Coblation versus dissection tonsillectomy in children
}

\begin{abstract}
Background and objective: Tonsillectomy is the surgical procedure of removing the tonsils. Various methods of tonsillectomy have been practiced aimed at decreasing or eliminating intraoperative and postoperative morbidity. This study was conducted to determine the different outcomes of tonsillectomy surgery in both coblation and dissection techniques.
\end{abstract}

Methods: A prospective control study was conducted with a total sample size of 66 patients. Each patient underwent tonsillectomy by using ArthroCare Coblator on the right side and dissection method on the left side. Children between the age of 3-12 years old were selected with indications of recurrent tonsillitis and/or kissing tonsil causing snoring and/or sleep apnea. Children with peritonsillar abscess, malignancy, bleeding disorder were excluded. Operative time and blood loss, postoperative pain, bleeding and healing process were compared between two methods. Operations performed by the same surgeon.

Results: The intraoperative time was significantly shorter $(P<0.001)$ and intraoperative blood loss was significantly lesser $(P<00.01)$ in coblation as compared to dissection tonsillectomy, while there were no significant differences in the postoperative pain scores on $1^{\text {st }}, 2^{\text {nd }}, 7^{\text {th }}$ and $14^{\text {th }}$ postoperative days. There was a significant healing process in tonsillar fossa in favor of coblation rather than dissection. No primary or secondary postoperative bleeding was reported.

Conclusion: Coblation tonsillectomy is a safe procedure with significantly less intraoperative time and less blood loss and better surgical wound healing with similar postoperative pain in comparison with dissection tonsillectomy.

Keywords: Tonsillectomy; Coblation; Dissection; Radiofrequency.

\section{Introduction}

The palatine tonsil consists of paired of lymphoid tissue found in the lateral walls of the oropharynx within a tonsillar fossa which formed by three pharyngeal muscles primarily the superior constrictor. ${ }^{1}$ Tonsillectomy is one of the most common surgical procedures performed in Otolaryngology. Several different techniques for performing tonsillectomy have been described as attempts to lower the inherent morbidity of this surgery. ${ }^{2,3}$ Described techniques include blunt dissection, gullitone excision, cryosurgery, monopolar and bipolar diathermy dissection, bipolar scissors dissection, ultrasonic scalpel, tonsillectomy, laser dissection and recently introduced coblation- assisted tonsillectomy. There is still controversy over which is the optimal technique of tonsillectomy with the lowest morbidity rates. ${ }^{4,5}$ Dissection tonsillectomy remains the most commonly performed tonsillectomy technique. In this procedure tonsillectomy performed by grasping the tonsil by tonsil holder forceps and pulling it medially then doing an incision in the mucous membrane where it reflects from the tonsil to anterior pillar. After complete dissection, the surgeon will clamp the lower pole and ligate it. Bleeding is mainly venous and hemostasis may be achieved

* Department of Surgery, College of Medicine, Hawler Medical University, Erbil, Iraq. 
by packing, diathermy and/or ligation. ${ }^{6}$ Unlike most operative procedures, which are closed primarily, tonsillectomy procedure an open wound that heals by secondary intention. ${ }^{7}$ Coblation is a unique modality that can ablate tissue by generating a field of ionized sodium molecules. The device uses bipolar radiofrequency energy to ablate and coagulate soft tissue into an ionized plasma layer. Where this plasma layer meets the tissue, there is adequate energy to break molecular bonds, resulting in molecular dissociation. Because this effect is achieved at a temperature of approximately $40 \mathrm{C}-70 \mathrm{C}$, thermal damage to the tissue is minimized. However, there is a significant cost implication to the use coblator device. $^{8,9}$ A new technique for tonsillectomy should be comparable to, or better than existing techniques in the areas of morbidity and mortality, be safe to use, have a short learning curve, and be cost effective. In particular, it preferably would be associated with less postoperative pain, less intraoperative blood loss, allow the most rapid return to normal diet and activity and carry a lower risk of both reactive and secondary hemorrhage. ${ }^{10}$ The aim of this study was to compare coblation tonsillectomy with the classical dissection method especially regarding the time of surgery, the blood loss peroperatively, the postoperative healing process and any possible complications.

\section{Methods}

A prospective control study with a total sample size of 66 patients. Each patient underwent tonsillectomy by using ArthroCare Coblator on the right side and dissection method on the left side. The study period was six months starting from $1^{\text {st }}$ August 2015 to $31^{\text {st }}$ January 2016 in Otolaryngology Department at Rizgary Teaching Hospital- Erbil city. Children between the age of 3-12 years old are selected for tonsillectomy with indications of (recurrent tonsillitis and/or kissing tonsil causing snoring and/or sleep apnea) using
ArthroCare Coblator on the right side and dissection method on the left side. Children with peritonsillar abscess (quinsy), suspected malignancy, history of the bleeding disorder are excluded in this study. Before commencement, the study protocol was approved by the Hawler Medical University, College of Medicine ethics committee and informed consent was taken from all the 66 patients' parents before participation in this study. After thorough history taking and medical examination, investigations are performed pre-operatively including complete blood count, blood group and Rh, clotting time, bleeding time and important virological tests. All operations were done under general anesthesia with endotracheal intubation. The patient is placed under sister rose tonsillectomy position as there is virtually no aspiration of blood or secretion into the airway. Boyle-Davis mouth gag was introduced and opened. These were held in position by a Draffins bipod. In left side dissection tonsillectomy technique, the tonsil was grasped with tonsil holding forceps and pulled medially. The incision was made in the mucous membrane where it reflects from the tonsil to anterior pillar. It may be extended along the upper pole to mucous membrane between the tonsil and posterior pillar, the lower pole of tonsil was clamped and ligated, hemostasis was secured with ligature using silk number 2; no electro -cautery was used for hemostasis. In right side coblation tonsillectomy technique, the tonsil excised by using the ArthroCare ENT Coblator II surgery system with Evac 70 plasma wands (ArthroCare Corp; Sunnnyvale, CA, USA). The wand comprises five active electrodes located at the distal end of the tip with the exposed portion of the shaft acting as the return electrode just proximal to the active electrodes. Settings were standardized at seven for coblation and three for coagulation. Each tonsillectomy technique intra-operatively was assessed for; operative time ( i.e. time from the first 
incision to complete hemostasis of the tonsillar bed); and the amount of blood loss by measuring blood collected in the suction bottle after subtracting the volume of saline used for cobaltion method and care not to use swabs as much as possible. Postoperatively, all patients were kept in the hospital and monitored for 6 hours. They were then discharged after being given the same treatment of antibiotics (oral Amoxicillin+Clavulanic acid 312 (250/62) $\mathrm{mg} / 5 \mathrm{ml}$ suspension in a dose of $50 \mathrm{mg} / \mathrm{kg} /$ day in three divided doses) for one week and analgesics in the form of Acetaminophen $10-15 \mathrm{mg} / \mathrm{kg} /$ orally every 6 hours for one week. Patients with hypersensitivity to penicillin had been given oral erythromycin $30-50 \mathrm{mg} / \mathrm{kg} / \mathrm{day}$ in four divided doses for one week. Patient's parents were given instructions regarding medication at home and information regarding food type intake like a soft diet for few days post-operatively and general care. All participant ${ }^{\mathrm{s}}$ parents were asked to fill out a pain diary including the day of operation (day 0 ), $1^{\text {st, }} 7^{\text {th }}$ and $14^{\text {th }}$ day after surgery, the diary included a commonly used standardized pain scale (Wong-Baker FACES pain rating scale) which is from 0 (no pain) to 10 (most severe pain) numerical rating scale with correlating faces (from happy to sad) and depending on the parents feeling of their children expression or feeling. ${ }^{11}$ All patients were followed up for two weeks by contacting their parents by telephone on the evening of the day of surgery (zero-day) and the $1^{\text {st }}$ post-operative day only. The degree of pain of the throat was to be marked on the scale first thing each morning, before taking any analgesic medication. Patients were all seen in the outpatient department on the $7^{\text {th }}$ and $14^{\text {th }}$ postoperative days and examination of their throat were carried out with a subjective measure the area of the tonsillar fossa that was healed or covered with slough (thin membrane or thick slough). The thin membrane means only cover the tonsillar fossa while thick membrane means the slough cover the tonsillar fossa as well as pillars and extending to surrounding mucosa. Data were analyzed using the statistical package for the social sciences (version 19). Chi-square test was used to compare between proportions. Paired t-test was performed to compare the mean pain score differences of both coblation and dissection tonsillectomy. A $P$ value of equal or less than 0.05 was considered statistically significant.

\section{Results}

A total of 66 patients were enrolled in this prospective study. Their age ranged from 3 to 12 years with a mean of 5.66. Sex distributions were $34(52 \%)$ male and $32(48 \%)$ female and age distribution frequency as shown in Figure 1 and Table 1.

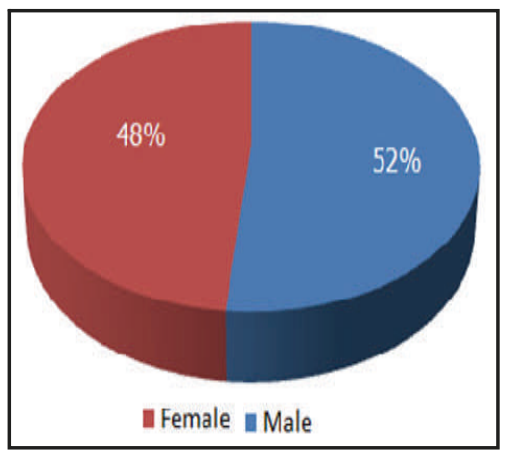

Figure 1: Sex distribution.
Table 1: Age group distribution.

\begin{tabular}{lcc}
\hline Age group & Frequency & Percent \\
\hline $3-5$ & 38 & 57.6 \\
$6-8$ & 20 & 30.3 \\
$9-12$ & 8 & 12.1 \\
Total & 66 & 100.0 \\
\hline
\end{tabular}


The main indication of tonsillectomy in this study was for recurrent tonsillitis; 24 out of $66(36 \%)$, Table 2. Surgery time was found to be statistically significant between coblation and dissection method. The mean operative time was 3.38 minutes (range 1.35-7.50 minutes) in coblation and 5.67 minutes (range $3.25-12.50 \mathrm{~min}$ ) in dissection $(P<0.001)$ as shown in Figure 2. Intraoperative blood loss was found to be statistically significant between the coblation and dissection. The mean blood loss was $9.61 \mathrm{ml}$ (ranged $0-25 \mathrm{ml}$ ) in coblation and $26.18 \mathrm{ml}$ (range10-50 ml) in dissection $(P<0.001)$ as shown in Figure 3.

Table 2: Indication of tonsillectomy.

\begin{tabular}{lcc}
\hline Indication of operation & Frequency & Percent \\
\hline Recurrent tonsillitis & 24 & 36.36 \\
Kissing tonsil causing snoring \&/or sleep apnea & 20 & 30.30 \\
Recurrent \&Kissing tonsil & 22 & 33.33 \\
Total & 66 & 100.0 \\
\hline
\end{tabular}

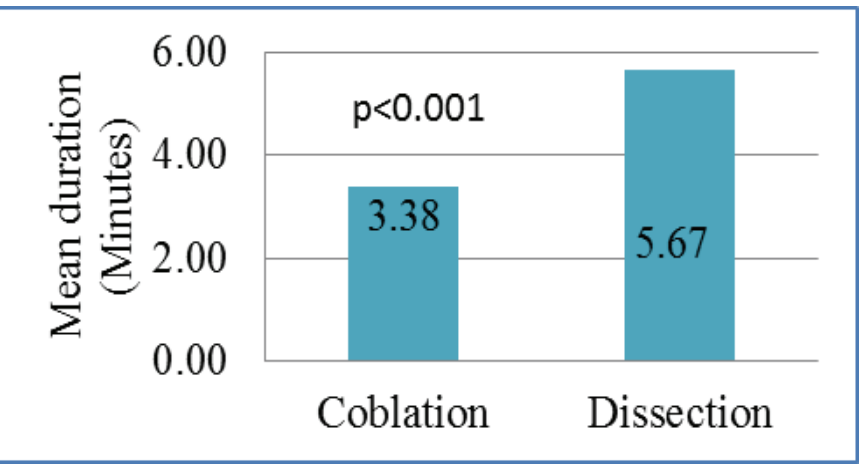

Figure 2: Mean duration of operation in minutes between coblation \& dissection.

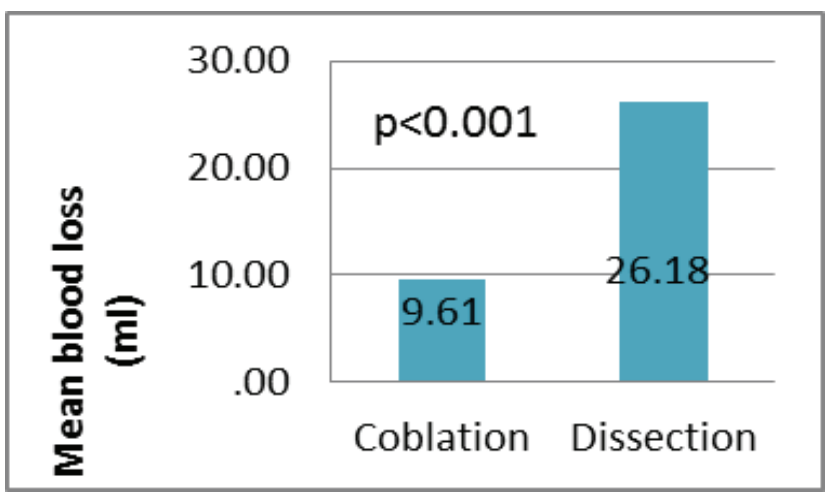

Figure 3: Mean intraoperative blood loss in $\mathrm{ml}$ between coblation \& dissection. 
The pain score was calculated for each patient from the day of operation (day 0 ), $1^{\text {st }}, 7^{\text {th }}$ and $14^{\text {th }}$ day after the operation and statistical information obtained for the cobaltion and dissection, although mean pain score is lower in coblation group but is not statistically significant (Table 3 ). No primary or secondary hemorrhage was reported. The development of the thick membrane (membrane covers the tonsillar bed, anterior pillar, posterior pillar and soft palate) was seen more with coblation in both the $7^{\text {th }}$ and $14^{\text {th }}$ post-operative days and the difference was highly significant (Table 4).

\section{Discussion}

A prospective study between coblation versus dissection method for 66 patients shows a statistically significant difference in mean intraoperative blood loss in favor of coblation method. Similar results were seen in the studies done by Zainon $\mathrm{IH}$ et al., ${ }^{12}$ Matin MA, ${ }^{13}$ Businco and Tirelli, ${ }^{3}$ and
Magdy et al. ${ }^{14}$ Probably due to coblation technique which uses radio-frequency to cut and coagulate tissue simultaneously causing a decrease in intraoperative blood loss. In our study operative time was shorter in coblation. Same results obtained in Zainon $\mathrm{IH}$ et al., and Matin MA studies. However, Tirelli showed that dissection takes less time and Magdy et al. study found no statistically significant difference. These different results are mostly due to the familiarity and experience of the surgeon with each method. Regarding postoperative pain, in our study mean pain score was calculated for each patient from the day of operation (day Zero), $1^{\text {st }}, 7^{\text {th }}$ and $14^{\text {th }}$ post-operative days. Statistically, there was no significant pain score between coblation and dissection side, however, coblation associated with lower mean pain score than dissection, especially on the day of surgery and $1^{\text {st }}$ post-operative days. This result was supported by a study done by Zainon $\mathrm{HI}$ et al. (2014), which showed

Table 3: Mean pain score differences of both coblation \& dissection tonsillectomy.

\begin{tabular}{lcccc}
\hline Postoperative pain & $\mathbf{N}$ & Mean & ISD & $\boldsymbol{P}$ values \\
\hline 0 day Coblation & 66 & 1.69 & 1.095 & \multirow{2}{*}{0.255} \\
0 day Dissection & 66 & 1.93 & 1.311 & \\
1st day Coblation & 66 & 1.52 & 0.932 & \multirow{2}{*}{0.249} \\
1st day Dissection & 66 & 1.73 & 1.144 & \\
7th day Coblation & 66 & 0.61 & 1.05 & \multirow{2}{*}{0.559} \\
7th day Dissection & 66 & 0.73 & 1.295 & \\
14th day Coblation & 66 & 0.12 & 0.328 & \multirow{2}{*}{0.284} \\
14th day Dissection & 66 & 0.21 & 0.595 & \\
\hline
\end{tabular}

Table 4: Throat examination on $7^{\text {th }} \& 14^{\text {th }}$ post-operative day.

\begin{tabular}{llccc}
\hline \multirow{2}{*}{ Time } & & \multicolumn{2}{c}{ Frequency $(\%)$} & \multirow{2}{*}{ Thalue } \\
& & Thin membrane & Thick membrane & P \\
\hline $7^{\text {th }}$ post- operative day & Coblation & $36(54.5 \%)$ & $30(45.5 \%)$ & \\
& Dissection & $60(90.90 \%)$ & $6(9.09 \%)$ & $<0.001$ \\
& Coblation & $46(69.69 \%)$ & $20(30.30 \%)$ & \\
$14^{\text {th }}$ post-operative day & Dissection & $58(87.87 \%)$ & $8(12.12 \%)$ & 0.038 \\
& & & & \\
\hline
\end{tabular}


that there was no difference in postoperative pain between two methods at $1^{\text {st }}, 2^{\text {nd }}$ and $3^{\text {rd }}$ post -operative days. However, there was significantly less pain in the coblation side $(P<0.001)$ at first six hours after operation. ${ }^{12}$ Shapiro and Bhattacharryya (2007) compared the intraoperative efficiency and postoperative recovery between dissection and coblation tonsillectomy (age 2-16) over 14 postoperative days, including the day of operation, found that there was no statistically significant difference in the mean pain scores between two procedures and this result is similar to the result of our study. ${ }^{15}$ In another study done by Parker et al. (2009), with respect to postoperative pain and return to normal diet, he discovered that coblation did not offer the significant advantage over dissection method. ${ }^{9}$ In addition, another study done by Businco \& Tirelli (2011), showed that the day of pain-free was 4.8 vs. 9.4 for dissection, also coblation group stopped liquid diet sooner (day 5 vs. day 9) and lost fewer school days than dissection children. ${ }^{3}$ Roje et al. (2009) did a comparison study between the two techniques; he revealed that children operated on by coblation technique faster resumed normal physical activities in 2 vs. 4 days and the result was statistically significant. ${ }^{7}$ Pain is a very difficult response to the study, as it is a very subjective symptom with significant inter- patient variability. It will probably vary from person to person even if all other factors stay constant. Thus a fixed amount of pain generated by a single procedure may be relatively mild for an individual with a high threshold of pain, while it may be perceived as severe pain for another individual who has a low threshold for pain. This might account for the lack of significant difference in the daily visual analog scores for pain between groups of patients in these studies. Also, the difference in their results may be due to that they perform both procedures in each case which is very difficult for a child to localize the side of pain. There were no episodes of primary or secondary hemorrhage in any patients in our study. In other studies also showed no episodes of postoperative bleeding in both methods. ${ }^{7,16}$ However, there was a study done by Shapiro \& Bhattachacharyya (2007) they showed that there was one postoperative bleeding in the coblation group on the $6^{\text {th }}$ postoperative day, this patient was treated with operative control of the bleeding without blood transfusion. ${ }^{15}$ Windfuher et al. (2005) report a higher rate of postoperative hemorrhage in children operated on by the coblation $(7.9 \%$ vs. $0.8 \%$ in dissection group). ${ }^{17}$ Regarding the result of our study, probably in a larger group sample size and longer duration study may give a different outcome of postoperative bleeding. In contrast, Bellosso et al. (2003) showed that the technique of coblation significantly reduced the rate of postoperative bleeding, especially in the pediatric population (0.95\%vs. $4.77 \%$ in dissection group). ${ }^{4}$ Regarding the development of thick membrane in our study, there were more in coblation at both $7^{\text {th }}$ and $14^{\text {th }}$ postoperative days. This result was statistically significant in coblation rather than dissection. In contrast, Magdy et al. (2008), did a study, which compared coblation tonsillectomy with dissection -ligation, monopolar electrocautery and $\mathrm{Co}_{2}$ laser tonsillectomies, which showed that there was no significant difference in the healing process between coblation and dissection method. ${ }^{14}$ However, Matin (2006) conducted a study examining the throat on the $8^{\text {th }}$ day after surgery; he found that there was a large difference in the healing process of the tonsillar fossa with nearly all the cobaltion fossa fully healed and considerable slough/granulation tissue with dissection side. ${ }^{13}$ In addition, a study conducted by Paramasivan et al. (2011), showed that some amount of poor healing was observed with the dissection method. ${ }^{18}$ 


\section{Conclusion}

Coblation tonsillectomy is a safe procedure with significantly less operative time and blood loss with similar postoperative pain in comparison with dissection tonsillectomy.

\section{Competing interests}

The authors declare that they have no competing interests.

\section{References}

1. Anniko M, Bernal SM, Bonkowsky V, Bradley $P$, Iurato S. Otorhinolaryngology Head and Neck Surgery. Munich: Springer; 2010. P. 426.

2. Özler GS, Tatar EC. Comparing Traditional Cold Knife Tonsillectomy with a New Technique Plasma Knife Tonsillectomy. Turk Arch Otolaryngol 2013; 51:114-7.

3. Businco LDR, Tirelli GC. Pediatric Tonsillectomy: Radiofrequency- Based Plasma Dissection Compared to Cold Dissection with sutures. $\{$ www.businco.it $\}$ [citedat Jan.19 ${ }^{\text {th }}$-2016]. Available from [http://www.businco.it/studio].

4. Belloso A, Chidambaram A, Morar P, Timms MS. Coblation Tonsillectomy Versus Dissection Tonsillectomy: Postoperative Hemorrhage. The Laryngoscope 2003; 113(11):2010-3.

5. Back L, Paloheimo M, Ylikoski J. Traditional Tonsillectomy Compared With Bipolar Radiofrequency Thermal Ablation Tonsillectomy in Adults. Arch Otolaryngol Head Neck Surg 2001; (127):1106-10.

6. Jalizada AN, Febohns, Al Rawi M. Comparison of cold tonsillectomy and cobilation tonsillectomy. Int J Tech Res App 2015; 3(1):123-7.

7. Roje Z, Racic G, Dogas Z, Pisac VP, Timms M. Postoperative Morbidity and Histopathologic Characteristics of Tonsillar Tissue Following Coblation Tonsillectomy in Children: A Prospective Randomized Single-Blind Study. Coll Antropol 2009; 33(1):293-8.

8. Chang KW. Randomized controlled trial of coblation versus electrocautery tonsillectomy. Otolaryngol Head Neck Surg 2005; 132: 273-80.

9. Parker D, Howe L, Unsworth V, Hilliam R. A randomised controlled trial to compare postoperative pain in children undergoing tonsillectomy using cold steel dissection with bipolar hemostasis versus coblation technique. Clin Otolaryngol 2009; 34:225-31.

10. Oko MO, Ganly I, Loughran S, Clement W A, Young D, Geddes NK. A Prospective Randomized Single-Blind Trail Comparing Ultrasonic Scalpel Tonsillectomy with Tonsillectomy by Blunt Dissection in a Pediatric Age Group. Glasgow, United Kingdom. Otolaryngol Head Neck Surg 2005; 133(4):579-84.
11. Wong D, Baker C. Pain in children: comparison of assessment scales. Pediatr Nurs 1988; 14:9-17.

12. Zainon IH, Salim R, Daud MK. Coblation tonsillectomy versus dissection tonsillectomy: A comparison of intraoperative time, intraoperative blood loss \&postoperative pain. Med J Malaysia 2014; 69(2):74-8.

13. Matin MA. Coblation tonsillectomy versus blunt dissection tonsillectomy. The ORION Med J 2006; 23:330-1

14. Magdy EA, Elwany S, El-Daly AS, Abdel-Hadi M, Morshedy MA. Coblation tonsillectomy: a prospective, double-blind, randomized, clinical and histopathological comparison with dissection-ligation, monopolar electrocautery and laser tonsillectomies. J Laryngol Otol 2008; 122: 282-90.

15. Shapiro N L, Bhattacharyya N. Cold Dissection Versus Coblation-Assisted Adenotonsillectomy in Children. Laryngoscope 2007; 117:406-10.

16. Timms MS, Temple RH, Paediatric coblation tonsillectomy. Int J Pediatr Otorhinolaryngol 2001; 61(3):195-8.

17. Windfuher JP, Deck JC, Remmert $S$. Hemorrhage following coblation tonsillectomy. Ann Otol Rhinol Laryngol 2005; 114(10):749-56.

18. Paramavasivan VK, Arumugam SV, Kameswaran M. Randomised comparative study of adenotonsillectomy by conventional and coblation method for children with obstructive sleep apnea. Int $J$ Pediatr Otorhinolaryngol 2012; 76(6):816-21. 